\title{
c-Fos expression in preoptic nuclei as a marker of sleep rebound in the rat
}

\author{
Daniela Dentico, ${ }^{1}$ Roberto Amici, ${ }^{1}$ Francesca Baracchi, ${ }^{1,2}$ Matteo Cerri, ${ }^{1}$ Elide Del Sindaco, ${ }^{1}$ Marco Luppi, ${ }^{1}$ \\ Davide Martelli, ${ }^{1}$ Emanuele Perez ${ }^{1}$ and Giovanni Zamboni ${ }^{1}$ \\ ${ }^{1}$ Department of Human and General Physiology, Alma Mater Studiorum-University of Bologna, Piazza P.ta S. Donato, 2, I-40126 \\ Bologna, Italy \\ ${ }^{2}$ Research Division, Department of Anesthesiology, University of Michigan, Ann Arbor, MI, USA
}

Keywords: c-Fos, cold exposure, median preoptic nucleus, P-CREB, ventrolateral preoptic nucleus

\begin{abstract}
Thermoregulation is known to interfere with sleep, possibly due to a functional interaction at the level of the preoptic area (POA). Exposure to low ambient temperature $\left(T_{\mathrm{a}}\right)$ induces sleep deprivation, which is followed by sleep rebound after a return to laboratory $T_{\mathrm{a}}$. As two POA subregions, the ventrolateral preoptic nucleus (VLPO) and the median preoptic nucleus (MnPO), have been proposed to have a role in sleep-related processes, the expression of c-Fos and the phosphorylated form of the $\mathrm{CAMP}_{\mathrm{C}} \mathrm{Ca}^{2+}$ responsive element-binding protein (P-CREB) was investigated in these nuclei during prolonged exposure to a $T_{\mathrm{a}}$ of $-10^{\circ} \mathrm{C}$ and in the early phase of the recovery period. Moreover, the dynamics of the sleep rebound during recovery were studied in a separate group of animals. The results show that c-Fos expression increased in both the VLPO and the MnPO during cold exposure, but not in a specific subregion within the VLPO cluster counting grid (VLPO T-cluster). During the recovery, concomitantly with a large rapid eye movement sleep (REMS) rebound and an increase in delta power during non-rapid eye movement sleep (NREMS), c-Fos expression was high in both the VLPO and the MnPO and, specifically, in the VLPO T-cluster. In both nuclei, P-CREB expression showed spontaneous variations in basal conditions. During cold exposure, an increase in expression was observed in the MnPO, but not in the VLPO, and a decrease was observed in both nuclei during recovery. Dissociation in the changes observed between c-Fos expression and P-CREB levels, which were apparently subject to state-related non-regulatory modulation, suggests that the sleeprelated changes observed in c-Fos expression do not depend on a P-CREB-mediated pathway.
\end{abstract}

\section{Introduction}

The preoptic area (POA) is known to be a key structure in the regulation of body temperature (Romanovsky, 2007), and has been clearly recognized as a sleep-promoting site (Szymusiak et al., 2007), probably representing the diencephalic substrate of the integration between thermoregulation and sleep-related processes (Parmeggiani, 2003). A relevant feature of the POA is that almost $25 \%$ of neurons therein increase their activity at sleep onset and/or during sleep occurrence (Szymusiak et al., 2007). It has been proposed that two POA subregions, the ventrolateral preoptic nucleus (VLPO) and the median preoptic nucleus ( $\mathrm{MnPO})$, may have a key role in sleep-related processes on the basis of the results of unit recording (Szymusiak et al., 1998; Suntsova et al., 2002, 2007), anatomical tracer (Sherin et al., 1996, 1998; Steininger et al., 2001; Uschakov et al., 2007) and immunohistochemical studies (analysis of c-Fos expression) (Morgan \& Curran, 1991; Sherin et al., 1996; Gong et al., 2000, 2004). Sleep deprivation studies have suggested that, in both nuclei, c-Fos activation is related to sleep occurrence and/or to an increase in sleep pressure (Gong et al., 2004; Gvilia et al., 2006a,b).

Correspondence: Dr Giovanni Zamboni, as above.

E-mail: giovanni.zamboni@unibo.it

Received 4 December 2008, revised 11 June 2009, accepted 16 June 2009
Exposure to low ambient temperature $\left(T_{\mathrm{a}}\right)$ represents a useful tool for inducing physiological sleep deprivation, which is followed by a sleep rebound after a return to normal laboratory conditions (Parmeggiani, 2003). The thermoregulatory impairment that characterizes rapid eye movement sleep (REMS) makes cold exposure particularly challenging for REMS (Parmeggiani, 2003; Heller, 2005). In particular, during prolonged exposure to very low $T_{\mathrm{a}} \mathrm{s}$, REMS pressure was shown to increase dramatically, leading to an intense REMS rebound during the following recovery (Amici et al., 1994, 1998, 2008; Cerri et al., 2005). Extreme cold is apparently less challenging for non-rapid eye movement sleep (NREMS), as, under a 24-h exposure to a $T_{\mathrm{a}}$ of $-10{ }^{\circ} \mathrm{C}$ protocol, the changes in both NREMS amount and the power density in the delta band of the electroencephalogram were smaller than those observed in REMS amount, during both the exposure and the following recovery (Cerri et al., 2005).

In the present study, in order to better assess the role of the VLPO and $\mathrm{MnPO}$ in sleep-related processes under a long-term physiological sleep deprivation protocol, c-Fos expression was studied during prolonged exposure to a $T_{\mathrm{a}}$ of $-10^{\circ} \mathrm{C}$ and the subsequent early recovery at laboratory $T_{\mathrm{a}}$. In addition, as prolonged exposure to a $T_{\mathrm{a}}$ of $-10{ }^{\circ} \mathrm{C}$ was shown to dampen the maximum accumulation capacity of the second messenger cAMP at the POA level (Zamboni et al., 1996, 1999, 2004), the expression of the phosphorylated form of the 
constitutive transcription factor $\mathrm{cAMP} / \mathrm{Ca}^{2+}$-responsive elementbinding protein (P-CREB), a key activator of $c$-fos transcription (Herdegen \& Leah, 1998), was studied in parallel. Furthermore, sleep parameters were studied in a separate group of animals during early recovery following a 48 -h exposure to a $T_{\mathrm{a}}$ of $-10^{\circ} \mathrm{C}$, as data on the size of the NREMS rebound under these conditions were missing. Preliminary results have already been presented in abstract form (Del Sindaco et al., 2006; Dentico et al., 2008a,b).

\section{Materials and methods}

\section{Animals and experimental approaches}

Male Sprague-Dawley rats (Charles River; 250-300 g at the beginning of experimental sessions) were used. The animals were acclimated to a normal laboratory $T_{\mathrm{a}}$ and to a 12-h/12-h light/dark cycle (light: 09:00-21:00 h; 100-150 lux at cage level); food and water were available ad libitum. The experiments were approved by the Ethical Committee of the University of Bologna under the supervision of the National Health Authority (Ministero della Sanità) in accordance with European Union Directive 86/609/EEC. Animal care was under the direct control of the University Veterinary Service. The experiment was carried out on two separate groups of animals by means of two experimental approaches: one behavioral, studying the changes in the wake-sleep cycle; and the other immunohistochemical, studying cFos and P-CREB expression at the VLPO and MnPO levels.

\section{Wake-sleep study}

\section{Experimental plan}

Ten animals, previously adapted to normal laboratory conditions $\left(T_{\mathrm{a}}, 25.0 \pm 1.0^{\circ} \mathrm{C}\right)$, were placed under general anesthesia [diazepam (Valium; Roche, Basel, Switzerland), $5 \mathrm{mg} / \mathrm{kg}$, intramuscular, followed by ketamine-HCl (Ketalar; Parke-Davis, Milan, Italy), $100 \mathrm{mg} / \mathrm{kg}$, intraperitoneal] and were implanted epidurally with two stainless steel electrodes for electroencephalographic (EEG) recording. Also, a thermistor (B10KA303N; Thermometrics, Northridge, CA, USA) mounted inside the tip of a stainless steel needle was implanted to measure hypothalamic temperature $\left(T_{\text {hy }}\right)$. The plugs connecting electroencephalography electrodes and the thermistor to the recording apparatus were embedded in acrylic dental resin anchored to the skull by small stainless steel screws. The animals were allowed to recover from surgery and to adapt to the recording apparatus for at least 1 week. The rats were individually kept in Plexiglas cages, placed in a thermoregulated and sound-attenuated box, which, in turn, was placed in a soundattenuated room. The EEG activity, $T_{\text {hy }}$ and motor activity (MA) of each animal were continuously recorded during each experimental session, except between 09:00 $\mathrm{h}$ and 09:15 h, when cage bedding, water and food were changed.

The experimental protocol for EEG recordings consisted of consecutive 24-h recording sessions. Following 2 days of recording for the baseline condition, the animals were exposed for $48 \mathrm{~h}(n=10)$ to low $T_{\mathrm{a}}\left(-10.0 \pm 1.0^{\circ} \mathrm{C}\right)$. The exposure started at the onset $(09: 00 \mathrm{~h})$ of the light period of the light/dark cycle. Following cold exposure, the animals were allowed to recover at a $T_{\mathrm{a}}$ of $25^{\circ} \mathrm{C}$.

\section{Analysis of sleep-wake state data}

User software was developed (QUICKBASIC) to handle the data. In each experiment, the EEG signal was amplified and filtered (high-pass filter, $-40 \mathrm{~dB}$ at $0.35 \mathrm{~Hz}$; low-pass filter, $-6 \mathrm{~dB}$ at $60 \mathrm{~Hz}$; digital notch filter, $-40 \mathrm{~dB}$ at $50 \mathrm{~Hz}$ ), and after $\mathrm{AD}$ conversion (sampling rate: electroencephalography, $128 \mathrm{~Hz})$ stored on a PC $(486 / 100$ DX-4). The EEG signal was subjected to on-line fast Fourier transform, and EEG power values were obtained for 4-s epochs in the delta $(0.75-4.0 \mathrm{~Hz})$, theta $(5.5-9.0 \mathrm{~Hz})$ and sigma $(11.0-16.0 \mathrm{~Hz})$ bands. The $T_{\text {hy }}$ signal was amplified $\left(1^{\circ} \mathrm{C} / 1 \mathrm{~V}\right)$ before AD conversion (sampling rate, $8 \mathrm{~Hz}$ ). MA was monitored by means of a passive infrared detector (PID10; Siemens, Munich, Germany) placed at the top of each cage. The signal was amplified and integrated before AD conversion (sampling rate, $8 \mathrm{~Hz}$ ), to make the output proportional to the amplitude and duration of movement.

EEG signals, $T_{\text {hy }}$ and MA were visually scored to determine the beginning and end of each REMS episode. The main criteria used for this assessment were based on the analysis of EEG signals, MA, and $T_{\text {hy }}$ (Cerri et al., 2005). Particular consideration was given to the changes in $T_{\text {hy }}$. For example, a REMS episode was considered to have begun only if the EEG changes associated with this sleep stage (i.e. high theta power, low delta power, and low sigma power) were concomitant with an increase in $T_{\text {hy }}$. Moreover, a REMS episode was considered to be over only if the EEG and postural changes were associated with a decrease in $T_{\text {hy }}$. On the basis of these criteria, the transition periods from either NREMS to REMS or REMS to wakefulness were not scored as REMS. The time for the minimal duration of a REMS episode was fixed at $8 \mathrm{~s}$. Following the removal of REMS epochs and that of the 4-s epochs that showed EEG artifacts, an automatic procedure allowed us to separate being wakefulness from NREMS, according to a procedure that has been extensively discussed previously (Cerri et al., 2005).

Data relative to the first $5 \mathrm{~h}$ of the light period (09:00 $\mathrm{h}$ to 14:00 $\mathrm{h}$ ) of the baseline (BL) and of a 5 -h period at a $T_{\mathrm{a}}$ of $25^{\circ} \mathrm{C}$ following $48 \mathrm{~h}$ at a $T_{\mathrm{a}}$ of $-10^{\circ} \mathrm{C}\left(\mathrm{R}_{\mathrm{E} 48}\right)$ for the following sleep parameters are shown in the present article: (i) hourly amount of REMS; (ii) hourly amount of NREMS; and (iii) relative power density in the delta band of the electroencephalogram in NREMS. In order to allow a comparison of the intensity of the sleep rebound following either a $24-\mathrm{h}$ or a $48-\mathrm{h}$ exposure to a $T_{\mathrm{a}}$ of $-10{ }^{\circ} \mathrm{C}$, data relative to the 5 -h period of recovery at a $T_{\mathrm{a}}$ of $25^{\circ} \mathrm{C}$ following a 24 -h exposure to a $T_{\mathrm{a}}$ of $-10^{\circ} \mathrm{C}\left(\mathrm{R}_{\mathrm{E} 24}\right)(n=6)$ are also shown in the present article. This analysis represents a new elaboration of data from a previous experiment (Cerri et al., 2005).

\section{Statistical analysis}

Statistical analysis was performed by means of repeated measures ANOVA (SPSS 9.0; SPSS, Chicago, IL, USA) for both the time spent in NREMS and REMS and power density in the delta EEG band in NREMS. Significance levels were pre-set at $P<0.05$. A number of pre-selected post hoc comparisons, allowing the data relative to each 5 -h period of recovery $\left(\mathrm{R}_{\mathrm{E} 24} ; \mathrm{R}_{\mathrm{E} 48}\right)$ to be compared with the respective average $\mathrm{BL}$ values, were made by means of the modified $t$-statistics $\left(t^{*}\right)$ and Bonferroni's correction of the significance level (Wallenstein et al., 1980). Total degrees of freedom $[n k-1 ; n=$ number of subjects (six for $\mathrm{R}_{\mathrm{E} 24} ; 10$ for $\mathrm{R}_{\mathrm{E} 48}$ ); $k$ = number of treatments (10)] were partitioned as follows: between subjects $(n-1)$; within subjects $[n(k-1)]$, subdivided in between treatments $(k-1)$, and residual $[(n-1)(k-1)]$. Thus, the degrees of freedom for the residual were 45 for $\mathrm{R}_{\mathrm{E} 24}$ and 81 for $\mathrm{R}_{\mathrm{E} 48}$.

\section{Immunohistochemical approach}

\section{Experimental plan}

Twenty-four animals, previously adapted to the normal laboratory conditions $\left(T_{\mathrm{a}}, 23.0 \pm 1.0^{\circ} \mathrm{C}\right)$, were used. Animals were individually housed $24 \mathrm{~h}$ before the start of the experimental session. They were 
then randomly assigned to one of the following seven experimental conditions, starting at lights-on (Fig. 1): (i) two control conditions, in which animals were kept for either $5 \mathrm{~h}(\mathrm{C} 5, n=3)$ or $24 \mathrm{~h}(\mathrm{C} 24$, $n=3$ ) at normal laboratory $T_{\mathrm{a}}$, in order to match the time schedule of treatments; (ii) three cold exposure conditions, in which animals were kept for either $5 \mathrm{~h}(\mathrm{E} 5, n=4), 24 \mathrm{~h}(\mathrm{E} 24, n=3)$ or $48 \mathrm{~h}(\mathrm{E} 48, n=3)$ at low $T_{\mathrm{a}}\left(-10.0 \pm 1.0^{\circ} \mathrm{C}\right)$. The 5 -h exposure condition was introduced to test the acute response to cold exposure (Cano et al., 2003); and (iii) two recovery conditions, in which animals were allowed to spend $5 \mathrm{~h}$ at normal laboratory $T_{\mathrm{a}}$ after either a 24-h (R5E24, $n=4)$ or a 48 -h (R5-E48, $n=4)$ exposure to a $T_{\mathrm{a}}$ of $-10^{\circ} \mathrm{C}$.

During cold exposure, in order to maintain water availability, bottles were renewed twice a day. At the end of each experimental condition, rats were killed under ether anesthesia by intra-aortic perfusion with $300 \mathrm{~mL}$ of a cold fixative solution of $4 \%$ paraformaldehyde, preceded by a wash with $100 \mathrm{~mL}$ of cold $0.01 \mathrm{M}$ phosphate-buffered saline. The induction time of the ether anesthesia ranged from $1 \mathrm{~min} 40 \mathrm{~s}$ to $2 \mathrm{~min}$ $50 \mathrm{~s}$, a time largely insufficient to produce ether-induced P-CREB expression (Kovács \& Sawchenko, 1996). Brains were post-fixed in $4 \%$ paraformaldehyde (Sigma-Aldrich, St Louis, MO, USA) at $4{ }^{\circ} \mathrm{C}$ for $4-6 \mathrm{~h}$.

\section{Immunohistochemistry}

Following $60-72 \mathrm{~h}$ of immersion in a $20 \%$ sucrose solution, brains were frozen by dipping them for $10 \mathrm{~min}$ in 2-methylbutane (Merck, Darmstadt, Germany) cooled with dry ice, and were then stored at $-80^{\circ} \mathrm{C}$. The immunohistochemical procedures were carried out concurrently on subgroups of three brains. Consecutive coronal sections were cut at $40 \mu \mathrm{m}$ on a freezing microtome (Frigocut; Reichert-Jung, Leica Microsystems Nussloch GmbH, Wetzlar, Germany). Sections were processed as following: one out of every five was stained with cresyl violet [Paxinos \& Watson (1998), modified according to Geisler et al. (2002)], in order to reveal the anatomical structures; the other four out of the five were alternately processed for c-Fos and P-CREB immunohistochemistry, so that two sections out of five were stained for c-Fos antigen and two for P-CREB antigen.

For immunohistochemical staining, free-floating sections were incubated with rabbit anti-c-Fos primary antiserum (cat. no. PC38, Ab-5, 1 : 20 000; Calbiochem, La Jolla, CA, USA) or rabbit anti-

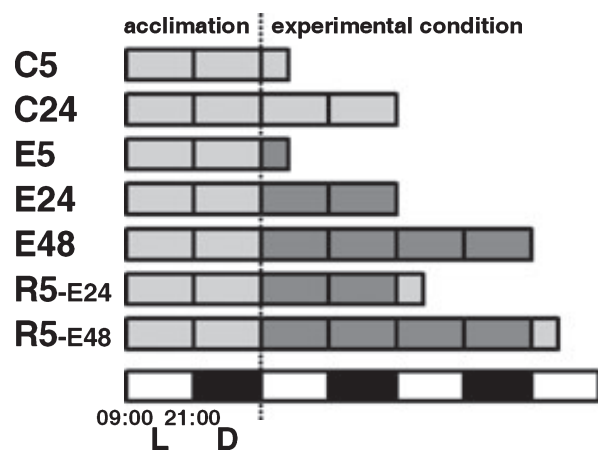

FIG. 1. Schematic representation of the experimental protocol. Each box represents either a 12 -h (long) or a 5 -h (short) period. The last $24 \mathrm{~h}$ of the acclimation period are also represented. Light gray, normal laboratory ambient temperature $\left(T_{\mathrm{a}} 23.0 \pm 1.0^{\circ} \mathrm{C}\right)$; dark gray, low $T_{\mathrm{a}}\left(-10.0 \pm 1.0^{\circ} \mathrm{C}\right) . \mathrm{L}$, light; $\mathrm{D}$, dark; C5, $5 \mathrm{~h}$ at a $T_{\mathrm{a}}$ of $23^{\circ} \mathrm{C}$; C24, $24 \mathrm{~h}$ at a $T_{\mathrm{a}}$ of $23{ }^{\circ} \mathrm{C}$; E5, $5 \mathrm{~h}$ at a $T_{\mathrm{a}}$ of $-10{ }^{\circ} \mathrm{C} ; \mathrm{E} 24,24 \mathrm{~h}$ at a $T_{\mathrm{a}}$ of $-10{ }^{\circ} \mathrm{C} ; \mathrm{E} 48,48 \mathrm{~h}$ at a $T_{\mathrm{a}}$ of $-10^{\circ} \mathrm{C} ; \mathrm{R} 5-\mathrm{E} 24,5 \mathrm{~h}$ at a $T_{\mathrm{a}}$ of $23{ }^{\circ} \mathrm{C}$ following $24 \mathrm{~h}$ at a $T_{\mathrm{a}}$ of $-10^{\circ} \mathrm{C}$; R5-E48, $5 \mathrm{~h}$ at a $T_{\mathrm{a}}$ of $23^{\circ} \mathrm{C}$ following $48 \mathrm{~h}$ at a $T_{\mathrm{a}}$ of $-10^{\circ} \mathrm{C}$.
P-CREB immunopurified IgG (cat. no. 06-519, 1 : 1000; Upstate, Lake Placid, NY, USA) on a shaking table for $72 \mathrm{~h}$ or $48 \mathrm{~h}$, respectively, at $4{ }^{\circ} \mathrm{C}$. For technical reasons, two different lots of the anti-P-CREB primary antibody were used for two different groups of 12 animals. The differences between the two lots were tested in the statistical analysis of the results, where a factor 'antibody lot' was introduced (see below). Sections were then incubated with a biotinylated goat anti-rabbit IgG (cat. no. BA-1000, 1 : 200; Vector Laboratories, Burlingame, CA, USA) for $2 \mathrm{~h}$ at room temperature, and subsequently reacted with biotinylated horseradish peroxidase preincubated with avidin (AB complex, cat. no. PK-4000, $1: 100$; Vector Vectastain $\mathrm{ABC}$ kit standard; Vector Laboratories) and developed with 3,3'-diaminobenzidine tetrahydrochloride (Sigma-Aldrich; $0.05 \mathrm{mg}$ per $100 \mathrm{~mL}$ ) to produce a brown reaction product in cell nuclei.

In order to test the specificity of antibodies, the primary antibody was routinely omitted and replaced with normal rabbit serum for c-Fos (cat. no. S-5000, 1 : 20 000; Vector Laboratories) and with normal rabbit IgG for P-CREB (cat. no. I-1000, 1 : 1000; Vector Laboratories) at the proper dilutions. The specificity of antibodies was also tested after the pre-adsorption of the primary antibody with a high concentration of the specific immunizing peptide [cFos peptide-2, cat. no. PP10, $10 \mu \mathrm{g}$ per $100 \mu \mathrm{L}$ antiserum (Calbiochem); P-CREB immunizing peptide, cat. no. 12-378, $10 \mu \mathrm{M}$ (Upstate)]. In both tests, nuclear staining was absent. After staining, the sections were mounted on gelatinized slides, dehydrated through graded alcohol, and coverslipped with DPX mountant for histology.

\section{Analysis of immunohistochemical data}

Images were acquired by means of a color digital video camera (CoolSnap, Pro Color; Media Cybernetics, Silver Spring, MD, USA) adapted to a Leitz Diaplan microscope (Leica Microsystems $\mathrm{GmbH}$, Wetzlar, Germany) equipped with a motorized $x y z$ stage (Media Cybernetics), under a $10 \times$ objective (with 0.30 numerical aperture) and standardized lighting conditions. The images were analysed blindly by using IMAge Pro Plus 4.5 (Media Cybernetics), without applying any adjustment for brightness or contrast. Digital images were segmented in order to separate the stained area from the background. The positive threshold value, identified in a pilot study to match visual counting, was normalized for each specimen on the basis of the background intensity value. For c-Fosstained sections, each object counted by the image analysis program was visually checked under the microscope in order to separate individual cell nuclei if they were clustered as a single object, carefully focusing up and down in order not to miss cell nuclei piled on top of one another; only objects exceeding $10 \mu \mathrm{m}^{2}$ were considered to be positive nuclei. This standardized method of cell counting was validated against two independent observers. For PCREB-stained sections, owing to the very large number of stained nuclei, the quantification was not made in terms of number of positive nuclei but in terms of the stained area. This method was previously validated by comparing the number of positive nuclei and the stained areas for c-Fos-stained sections.

All quantifications were calculated for standardized rectangular grids placed over the selected areas of interest (see Fig. 2 for depiction of the grids). The VLPO counting grids (Lu et al., 2002) were placed on all the immunohistochemically stained sections between $-0.05 \mathrm{~mm}$ and $-0.55 \mathrm{~mm}$ from bregma (Paxinos \& Watson, 2005): (i) the VLPO cluster grid was $300 \mu \mathrm{m}$ wide by $300 \mu \mathrm{m}$ high, placed along the base of the brain, with its far border $400 \mu \mathrm{m}$ lateral to the lateral edge of the optic chiasm, just medial to the diagonal band of Broca; (ii) the medial extended VLPO grid was medial to the VLPO cluster grid, $400 \mu \mathrm{m}$ 

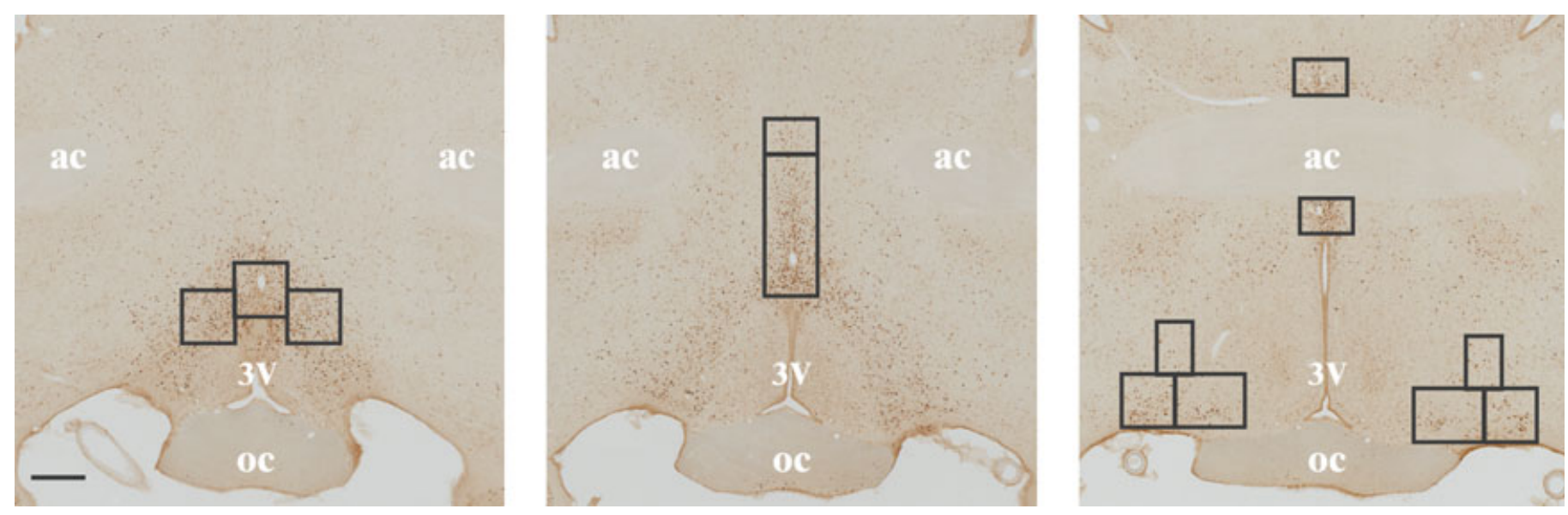

FIG. 2. Median preoptic nucleus (MnPO) and ventrolateral preoptic nucleus (VLPO) counting grids on three c-Fos-stained sections from a sample animal [5 h at ambient temperature $23{ }^{\circ} \mathrm{C}$ following $24 \mathrm{~h}$ at ambient temperature $-10{ }^{\circ} \mathrm{C}$ (R5-E24)], at the rostrocaudal levels of $+0.24 \mathrm{~mm}$ (left), $0.00 \mathrm{~mm}$ (center) and $-0.28 \mathrm{~mm}$ (right) from bregma (Paxinos \& Watson, 2005). Left: rostral MnPO counting grids. Center and top right: examples of the modular system of counting grids used for caudal dorsal (upper rectangle, over anterior commissure level) and caudal ventral (lower rectangle, under anterior commissure level) MnPO analysis. Bottom right: bilateral representation of the counting grid system for cluster (square, lateral), medial extended (lower rectangle) and dorsal extended (upper rectangle) VLPO. 3V, third ventricle; ac, anterior commissure; oc, optic chiasm. Scale bar: $300 \mu \mathrm{m}$

wide by $300 \mu \mathrm{m}$ high; and (iii) the dorsal extended VLPO grid was $200 \mu \mathrm{m}$ wide by $300 \mu \mathrm{m}$ high, positioned above the VLPO cluster and medial extended VLPO grids and centered over their border. The MnPO was examined at both the rostral and the caudal level: (i) the rostral MnPO grid was placed immediately over the vascular organ of the lamina terminalis, which surrounds the third ventricle ( $+0.40 \mathrm{~mm}$ to $+0.12 \mathrm{~mm}$ from bregma) (Paxinos \& Watson, 2005), and was composed of three $300 \times 300 \mu \mathrm{m}$ squares arranged in the shape of a horseshoe [with the two lateral frames shifted $150 \mu \mathrm{m}$ down in relation to the central frame; modified from Peterfi et al. (2004)]; (ii) the caudal ventral MnPO grid was placed immediately dorsal to the third ventricle, centered on the midline $(+0.12 \mathrm{~mm}$ to $-0.28 \mathrm{~mm}$ from bregma) (Paxinos \& Watson, 2005), extending $150 \mu \mathrm{m}$ from the midline bilaterally, and from $100 \mu \mathrm{m}$ to $800 \mu \mathrm{m}$, with $100-\mu \mathrm{m}$ steps, dorsally, according to the rostrocaudal changes in nucleus shape [modified from Gong et al. (2000)]; and (iii) the caudal dorsal MnPO grid was placed immediately dorsal to the anterior commissure level centered on the midline $(+0.04 \mathrm{~mm}$ to $-0.28 \mathrm{~mm}$ from bregma) (Paxinos \& Watson, 2005), extending $150 \mu \mathrm{m}$ from the midline bilaterally, and $100 \mu \mathrm{m}$ or $200 \mu \mathrm{m}$ dorsally according to the rostrocaudal changes in nucleus shape [modified from Gong et al. (2000)].

For each VLPO division, cell counts were made bilaterally in five sections for each antigen, and averaged to yield a single value for each rat and antigen. For the rostral, caudal ventral and caudal dorsal MnPO, cell counts were made in three, five and four sections, respectively, for each antigen and referred to the following dimensions of the counting grids: $900 \times 300 \mu \mathrm{m}$ for the rostral MnPO, $300 \times 600 \mu \mathrm{m}$ for the caudal ventral MnPO, and $300 \times 200 \mu \mathrm{m}$ for the caudal dorsal MnPO. They were then averaged to yield a single value for each rat and antigen. The sizes of both c-Fos-labeled and P-CREB-labeled nuclei were determined for each experimental condition and for each nucleus from an overall sample of 840 cell nuclei. As the diameters (mean \pm SEM) of c-Foslabeled $(12.32 \pm 0.15 \mu \mathrm{m})$ and P-CREB-labeled $(10.97 \pm 0.10 \mu \mathrm{m})$ nuclei were homogeneous among the seven experimental groups, and our experimental plan was only aimed at comparing experimental conditions, we did not use a correction factor for cell size to compare the different groups (Guillery \& Herrup, 1997).

\section{Statistical analysis}

Statistical analysis was performed with SPSS 9.0 (SPSS). As the standard deviation and the mean of the samples varied in direct proportion, logarithmic (ln) transformation of the data was performed (Snedecor \& Cochran, 1991). For each nucleus, antigens were analysed separately, and the experiment was organized according to a factorial $(a \times b)$ design. Factor $a$, the nuclear division factor, had three levels for VLPO (VLPO cluster, medial extended VLPO, and dorsal extended VLPO) and three levels for MnPO (rostral MnPO, caudal ventral $\mathrm{MnPO}$, and caudal dorsal MnPO). Factor $b$, the experimental condition factor, had seven levels (C24, E24, E48, C5, E5, R5-E24, and R5-E48) for both nuclei. Only for P-CREB antigen was the experimental plan modified to a three-level factorial $(a \times b \times c)$ design, in which factor $c$ had two levels (antibody lot 1 and antibody lot 2), in order to test a possible influence of the different lots on the results.

Results were evaluated by using univariate analysis of variance (ANOVA). Significance levels were pre-set at $P<0.05$. Pre-planned contrasts (between mean values of grouped data) were carried out according to the following: (i) (C24/E24/E48) vs. (C5/E5/ R5-E24/R5-E48); (ii) (E24/E48) vs. C24; (iii) E48 vs. E24; (iv) (C5/R5-E24/R5-E48) vs. E5; (v) (R5-E24/R5-E48) vs. C5; and (vi) R5-E48 vs. R5-E24. Pre-selected post hoc comparisons were also set: C5 vs. C24; E5 vs. C5; E24 vs. C24; E48 vs. C24; R5-E24 vs. C5; R5-E48 vs. C5; R5-E24 vs. E24; R5-E48 vs. E48; and (R5-E24/R5-E48) vs. (E24/E48). Significance levels were determined by means of the Fisher $F$-test for pre-planned contrasts and by means of $t^{*}$ and sequential Bonferroni correction of the significance level (Holm, 1979; Wallenstein et al., 1980) for post hoc comparisons. Total degrees of freedom $[n k-1 ; n=$ number of subjects (24); $k=$ number of independent measures in different nuclear divisions (3)] were partitioned as follows:

1. c-Fos: between groups, $a b-1$ [ $a$, levels of factor $a(3) ; b$, levels of factor $b(7)]$; within groups (residual), $(n k-1)-(a b-1)=71-20=$ 51. However, for c-Fos (VLPO), owing to the presence of a significant two-way interaction, three independent one-way ANOVAs were performed for each nuclear division, with degrees 

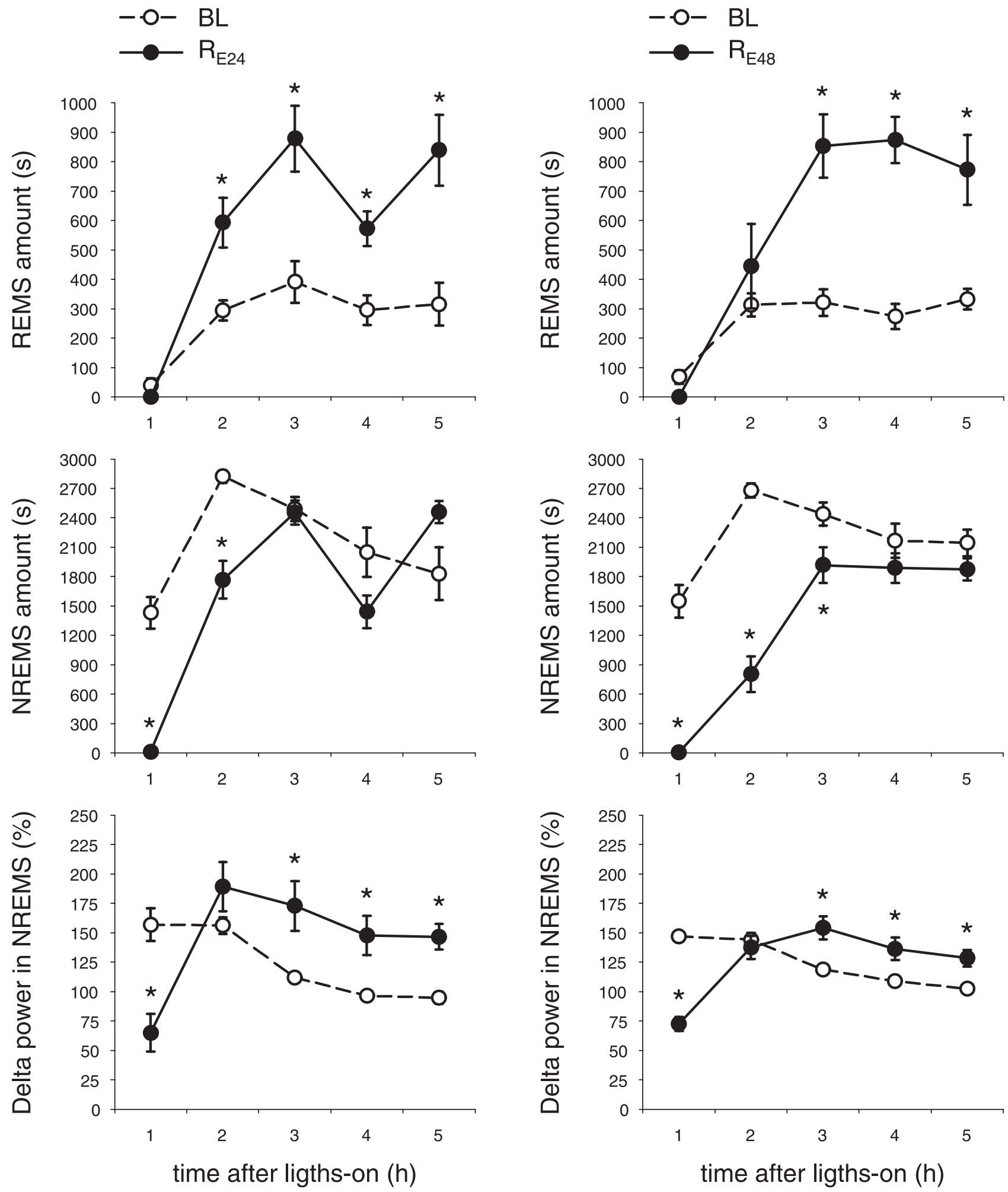

FIG. 3. Time spent (s) in rapid eye movement sleep (REMS, top) and in non-rapid eye movement sleep (NREMS, middle), and relative power density [percentage of average 24-h baseline (BL) levels] in the delta band (0.75-4.0 Hz) in NREMS (bottom) (mean \pm standard error of the mean, 1-h intervals) during either the BL at normal laboratory ambient temperature $\left(T_{\mathrm{a}}, 25.0 \pm 1.0^{\circ} \mathrm{C}\right.$, empty circles) or the early recovery period at normal laboratory $T_{\mathrm{a}}$ (filled circles) following a 24 -h (left column) or 48-h (right column) exposure to low $T_{\mathrm{a}}\left(-10.0 \pm 1.0^{\circ} \mathrm{C}\right)$. Statistically significant post hoc comparisons: $* P<0.05$, as compared with BL for REMS $\left[\left(\mathrm{R}_{\mathrm{E} 24}\right.\right.$ vs. BL: h $\left.2, t_{45} *=3.46, P=0.006 ; \mathrm{h} 3, t_{45} *=5.66, P<0.001 ; \mathrm{h} 4, t_{45} *=3.22, P=0.012 ; \mathrm{h} 5, t_{45} *=6.09, P<0.001\right)\left(\mathrm{R}_{\mathrm{E} 48}\right.$ vs. BL: h $3, t_{81} *=5.68$, $\left.\left.P<0.001 ; \mathrm{h} 4, t_{81}{ }^{*}=6.39, P<0.001 ; \mathrm{h} 5, t_{81} *=4.70, P<0.001\right)\right]$ and for delta power $\left[\left(\mathrm{R}_{\mathrm{E} 24}\right.\right.$ vs. BL: h $3, t_{45} *=3.73, P=0.003 ; \mathrm{h} 4, t_{45} *=3.15, P=0.014 ; \mathrm{h} 5$, $\left.t_{45} *=3.17, P=0.014\right)\left(\mathrm{R}_{\mathrm{E} 48}\right.$ vs. BL: h $3, t_{81} *=4.28, P<0.001 ; \mathrm{h} 4, t_{81} *=3.33, P=0.009$; h $\left.\left.5, t_{81} *=3.11, P=0.016\right)\right] . \mathrm{R}_{\mathrm{E} 24}, 5-\mathrm{h}$ period at a $T_{\mathrm{a}}$ of $25^{\circ} \mathrm{C}$ following $24 \mathrm{~h}$ at a $T_{\mathrm{a}}$ of $-10{ }^{\circ} \mathrm{C} ; \mathrm{R}_{\mathrm{E} 48,}, 5$-h period at a $T_{\mathrm{a}}$ of $25{ }^{\circ} \mathrm{C}$ following $48 \mathrm{~h}$ at a $T_{\mathrm{a}}$ of $-10{ }^{\circ} \mathrm{C}$. 
of freedom of the residual: $(n-1)-(b-1)=17$. For c-Fos $(\mathrm{MnPO})$, owing to the absence of a statistically significant interaction, degrees of freedom of the interaction $[(a-1)(b-1)]$ were kept in the residual: $51+12=63$.

2. P-CREB: between groups, $a b c-1[a$, levels of factor $a$ (3); $b$, levels of factor $b(7) ; c$, levels of factor $c$ (2)]; within groups (residual), $(n k-1)-(a b c-1)=71-41=30$. However, in both the VLPO and $\mathrm{MnPO}$, owing to the absence of statistically significant interactions, degrees of freedom of interactions [ $(a-1)(b-1)(c-1) ;(a-1)(b-1)$; $(a-1)(c-1) ;(b-1)(c-1)]$ were kept in the residual: $30+(12+12$ $+2+6)=62$.

\section{Results}

\section{Sleep-wake states}

As shown in Fig. 3, a clear sleep rebound was observed following both the 24-h and the 48 -h exposures to a $T_{\mathrm{a}}$ of $-10{ }^{\circ} \mathrm{C}$. In both $\mathrm{R}_{\mathrm{E} 24}$ and $\mathrm{R}_{\mathrm{E} 48}$, the REMS rebound was stronger than that of NREMS. Although the REMS rebound was apparently postponed by about $1 \mathrm{~h}$ in $\mathrm{R}_{\mathrm{E} 48}$, no major differences were observed between the two conditions from the third to the fifth hour of the recovery period, and, in particular, $166 \%$ and $133 \%$ increases in time spent in REMS as compared with BL levels was observed at the fifth hour in $\mathrm{R}_{\mathrm{E} 24}$ and $\mathrm{R}_{\mathrm{E} 48}$, respectively. In contrast, no significant rebound was observed in the time spent in NREMS. In both conditions, delta power was significantly increased in relation to the $\mathrm{BL}$ levels, starting from the third hour of the recovery, but only $55 \%$ and $25 \%$ increases were observed at the fifth hour in $\mathrm{R}_{\mathrm{E} 24}$ and $\mathrm{R}_{\mathrm{E} 48}$, respectively. Statistically significant comparisons for either REMS amount or delta power are shown in the legend to Fig. 3.

\section{Immunohistochemistry}

\section{c-Fos expression}

The degree of c-Fos expression in both the VLPO and MnPO is shown in Figs 4 and 5, respectively, and statistically significant comparisons are shown in the legends. The number of c-Fos-immunoreactive neurons (IRNs) increased in comparison with control levels during both the exposure to low $T_{\mathrm{a}}$ and the following recovery period in the three nuclear divisions of both the VLPO and MnPO. This increase was statistically significant for the whole MnPO and in each VLPO nuclear division, where separate analyses were carried out, owing to a significant interaction between the nuclear division and the experimental condition factors $\left(F_{12,51}=2.50, P=0.012\right)$.

Interestingly, relevant functional differences between exposure and recovery conditions were specifically observed in the VLPO cluster. In this nuclear division, not only were the numbers of c-Fos-IRNs significantly higher in animals that were allowed to recover than in those that were not, but a specific pattern of distribution of c-Fospositive nuclei was observed in the triangular area (VLPO T-cluster) within the square counting grid, whose use has been proposed in order to give a better demarcation of the cluster itself (Lu et al., 2000). As shown in Fig. 6 (left panel), almost no stain was observed during exposure within the VLPO T-cluster, whereas strong activation appeared during the recovery. The reverse pattern was observed during the prolonged exposure sessions, as an increase in c-Fos expression was observed outside of the VLPO T-cluster only.

\section{P-CREB expression}

The degree of P-CREB expression in both the whole VLPO and $\mathrm{MnPO}$ and the statistically significant comparisons are shown in
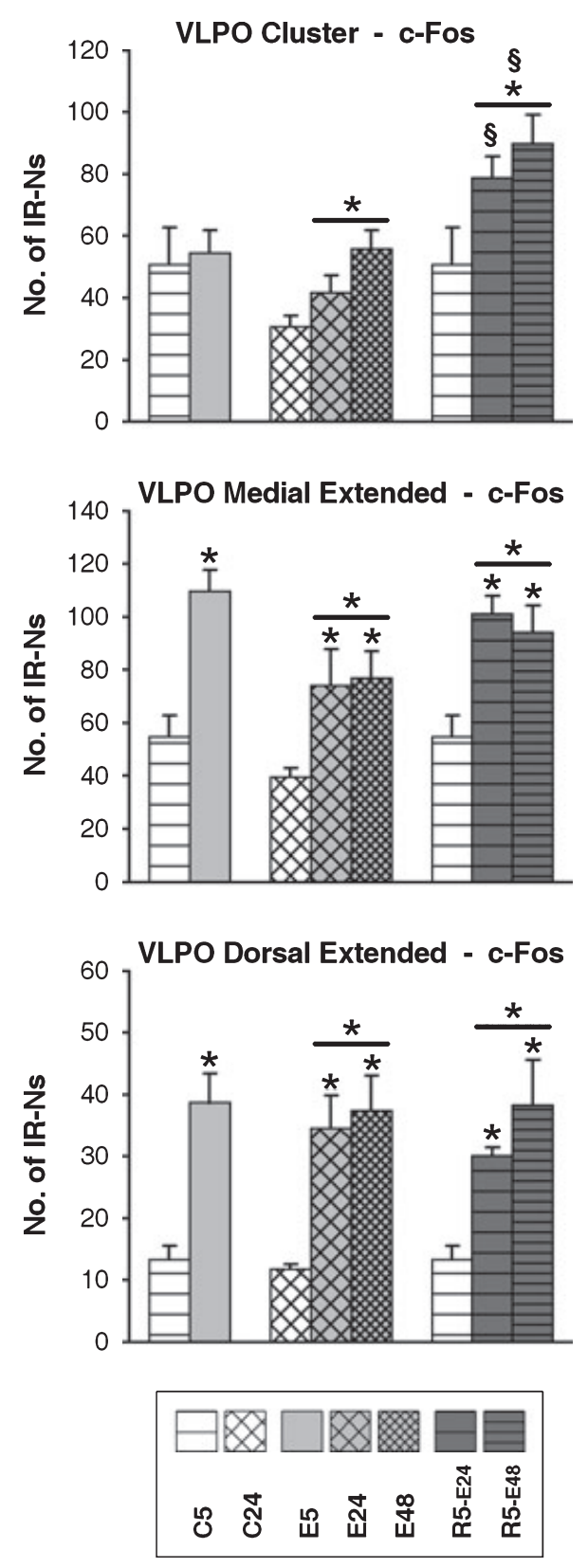

FIG. 4. Number (mean \pm standard error of the mean) of c-Fos-immunoreactive neurons (IRNs) in the three ventrolateral preoptic nucleus (VLPO) divisions (cluster, medial extended, and dorsal extended) in the different experimental conditions. The bar relative to the C5 condition is shown twice. Statistically significant pre-planned contrasts and post hoc comparisons are indicated: $* P<0.05$, as compared with the time-matched control for the VLPO cluster $\left[(\mathrm{E} 24 / \mathrm{E} 48)\right.$ vs. C24, $F_{1,17}=5.78, P=0.028 ;(\mathrm{R} 5-\mathrm{E} 24 / \mathrm{R} 5-\mathrm{E} 48)$ vs. C5, $\left.F_{1,17}=9.58, P=0.007\right]$, the medial extended VLPO [E5 vs. C5, $t_{17} *=4.45$, $P=0.003$; (E24/E48) vs. C24, $F_{1,17}=18.07, P=0.001$; E24 vs. C24, $t_{17} *=3.53, P=0.015$; E48 vs. C24, $t_{17} *=3.83, P=0.009$; (R5-E24/ R5-E48) vs. C5, $F_{1,17}=17.28, P=0.001 ;$ R5-E24 vs. C5, $t_{17} *=3.94$, $P=0.008$; R5-E48 vs. C5, $\left.t_{17}{ }^{*}=3.43, P=0.016\right]$, and the dorsal extended VLPO [E5 vs. C5, $t_{17} *=5.17, P=0.001$; (E24/E48) vs. C24, $F_{1,17}=32.98$, $P<0.001$; E24 vs. C24, $t_{17} *=4.79, P=0.001 ; \mathrm{E} 48$ vs. C24, $t_{17} *=5.15$, $P=0.001$; (R5-E24/R5-E48) vs. C5, $F_{1,17}=25.69, P<0.001$; R5-E24 vs. C5, $t_{17} *=4.05, P=0.004$; R5-E48 vs. C5, $\left.t_{17} *=4.93, P=0.001\right] ;{ }^{\S} P<0.05$ as compared with the relative exposure(s) for the VLPO cluster [(R5-E24/ R5-E48) vs. (E24/E48), $t_{17} *=3.85, P=0.012$; R5-E24 vs. E24, $t_{17} *=3.14$, $P=0.048]$. C5, $5 \mathrm{~h}$ at an ambient temperature $\left(T_{\mathrm{a}}\right)$ of $23^{\circ} \mathrm{C} ; \mathrm{C} 24,24 \mathrm{~h}$ at a $T_{\mathrm{a}}$ of $23{ }^{\circ} \mathrm{C}$; E5, $5 \mathrm{~h}$ at a $T_{\mathrm{a}}$ of $-10^{\circ} \mathrm{C}$; E24, $24 \mathrm{~h}$ at a $T_{\mathrm{a}}$ of $-10^{\circ} \mathrm{C} ; \mathrm{E} 48,48 \mathrm{~h}$ at a $T_{\mathrm{a}}$ of $-10{ }^{\circ} \mathrm{C}$; R5-E24, $5 \mathrm{~h}$ at a $T_{\mathrm{a}}$ of $23{ }^{\circ} \mathrm{C}$ following $24 \mathrm{~h}$ at a $T_{\mathrm{a}}$ of $-10^{\circ} \mathrm{C}$; R5-E48, $5 \mathrm{~h}$ at a $T_{\mathrm{a}}$ of $23^{\circ} \mathrm{C}$ following $48 \mathrm{~h}$ at a $T_{\mathrm{a}}$ of $-10^{\circ} \mathrm{C}$. 

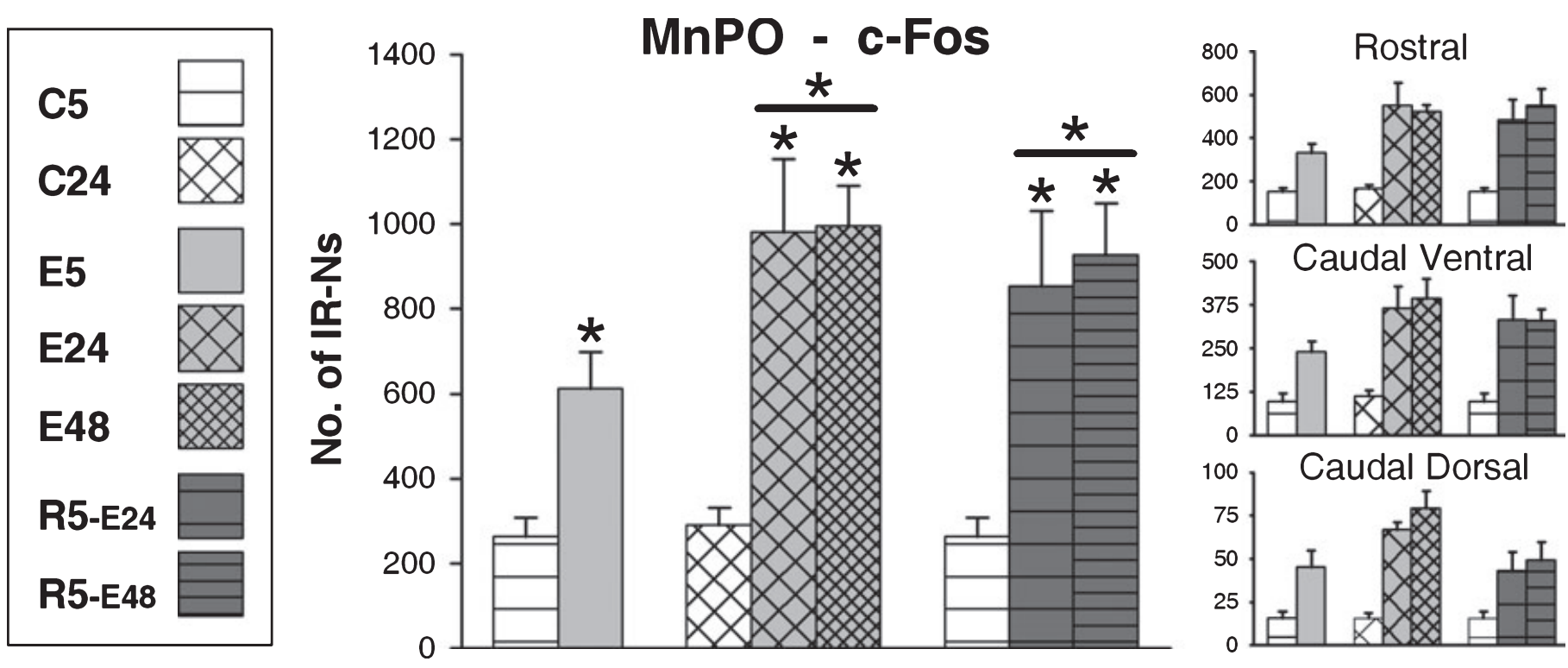

FIG. 5. Number (mean \pm standard error of the mean) of c-Fos-immunoreactive neurons (IRNs) in the median preoptic nucleus (MnPO) in the different experimental conditions. The bar relative to the $\mathrm{C} 5$ condition is shown twice. Bar charts are shown separately for the three MnPO divisions (rostral, caudal ventral, and caudal dorsal) in the right column. Statistically significant pre-planned contrasts and post hoc comparisons are indicated for the whole MnPO chart: $* P<.05$, as compared with the time-matched control [E5 vs. C5, $t_{63} *=6.61, P<0.001 ;(\mathrm{E} 24 / \mathrm{E} 48)$ vs. C24, $F_{1,63}=107.39, P<0.001 ; \mathrm{E} 24$ vs. C24, $t_{63} *=8.72, P<0.001 ; \mathrm{E} 48$ vs. $\mathrm{C} 24, t_{63} *=9.23, P<0.001$; (R5-E24/R5-E48) vs. C5, $F_{1,63}=89.81, P<0.001 ; \mathrm{R} 5$-E24 vs. C5, $t_{63} *=7.95, P<0.001 ; \mathrm{R} 5$-E48 vs. C5, $\left.t_{63} *=8.85, P<0.001\right]$. C5, $5 \mathrm{~h}$ at an ambient temperature $\left(T_{\mathrm{a}}\right)$ of $23{ }^{\circ} \mathrm{C} ; \mathrm{C} 24,24 \mathrm{~h}$ at a $T_{\mathrm{a}}$ of $23{ }^{\circ} \mathrm{C} ; \mathrm{E} 5,5 \mathrm{~h}$ at a $T_{\mathrm{a}}$ of $-10{ }^{\circ} \mathrm{C} ; \mathrm{E} 24,24 \mathrm{~h}$ at a $T_{\mathrm{a}}$ of $-10{ }^{\circ} \mathrm{C}$; E $48,48 \mathrm{~h}$ at a $T_{\mathrm{a}}$ of $-10{ }^{\circ} \mathrm{C} ; \mathrm{R} 5-\mathrm{E} 24$, $5 \mathrm{~h}$ at a $T_{\mathrm{a}}$ of $23{ }^{\circ} \mathrm{C}$ following $24 \mathrm{~h}$ at a $T_{\mathrm{a}}$ of $-10{ }^{\circ} \mathrm{C}$; R5-E48, $5 \mathrm{~h}$ at a $T_{\mathrm{a}}$ of $23{ }^{\circ} \mathrm{C}$ following $48 \mathrm{~h}$ at a $T_{\mathrm{a}}$ of $-10{ }^{\circ} \mathrm{C}$.

Table 1. Data from each of the VLPO and MnPO divisions are not shown, as the pattern of P-CREB expression was homogeneous in the different nuclear divisions of both nuclei. In both the VLPO and $\mathrm{MnPO}$, the pattern of changes in CREB phosphorylation did not appear to match that observed in c-Fos expression. In both nuclei, $\mathrm{P}-\mathrm{CREB}$ expression was found to be significantly higher in $\mathrm{C} 5$ than in C24. Cold exposure did not modify the levels of CREB phosphorylation as compared with the matched control values, except for an increase observed in the $\mathrm{MnPO}$ during prolonged exposure. In both nuclei, during the recovery, the staining remained at the same levels observed after the exposure, but it was significantly reduced as compared with that observed in C5. Interestingly, in contrast to c-FosIRNs, P-CREB-IRNs did not show any specific pattern of distribution within the VLPO cluster grid during the exposure and the following recovery period (Fig. 6, right panel).

\section{Discussion}

The main findings of the present study can be summarized as follows: (i) both the VLPO and MnPO are involved in sleep-related processes underlying the significant sleep rebound that follows the physiological sleep deprivation induced by prolonged cold exposure; (ii) VLPO and $\mathrm{MnPO}$ involvement was more evident from changes in c-Fos expression, which were apparently dissociated from those in CREB phosphorylation, suggesting that the sleep-related increase in c-Fos expression in both the VLPO and MnPO is not linked to a CREBmediated pathway; (iii) a sleep-related functional specificity for the VLPO cluster was observed, as a different pattern of distribution was found for neurons that were active during either the exposure or the following sleep rebound in relation to the triangular area (VLPO T-cluster), whose use has been proposed in order to give a better demarcation of the cluster itself (Lu et al., 2000); and (iv) during the recovery period, REMS rebound appeared to be more intense than
NREMS rebound, in agreement with changes in antigen expression in both the VLPO and MnPO.

The use of c-Fos detection in conditions of sustained challenges to local integrity or to body homeostasis (McKinley et al., 1994; Miyata et al., 1994, 1995; Brown \& Sawchenko, 1997; Patronas et al., 1998) has been questioned, because of the possibility that the primary antibody used may also recognize Fos-related antigens, which exhibit slower kinetics than c-Fos (Sharp et al., 1991). Nevertheless, this possibility was minimized in our study by the fact that the immunogen peptide for generating the primary antiserum corresponds to the N-terminal epitope 4-17 of human c-Fos, which shares little homology with known Fos-related antigens (Sharp et al., 1991). The use of P-CREB detection in conditions of sustained challenges has been recommended by Hoffman \& Lyo (2002) as a useful approach for monitoring changes in neuronal activity. In particular, it has been shown that the persistence in time of CREB phosphorylation can be linked to the duration of the stimulus (Wu et al., 2001).

Exposure to low $T_{\mathrm{a}}$ allows for physiological manipulation of the sleep-wake cycle. Nevertheless, as for any sleep-wake cycle manipulation procedure, the inherent problem of the attribution of the activation of neural substrates to either the increased sleep pressure or to the deprivation procedure itself arises while deprivation is in progress. At the POA level, extensive interweaving of the neural substrates involved in body temperature and sleep regulation has been observed (Romanovsky, 2007; Szymusiak et al., 2007; Nakamura \& Morrison, 2008). Functional integration between sleep and thermoregulation has been shown even at a cellular level in the POA, as either a wake-sleep-dependent discharge (Alam et al., 1995a, 1996) or wake-sleep-dependent modifications in thermosensitivity have been observed in thermosensitive neurons (Parmeggiani, 1987; Parmeggiani et al., 1987; Alam et al., 1995a,b, 1996). On this basis, body temperature and sleep regulatory processes may hardly be considered to be separable at the POA level. 

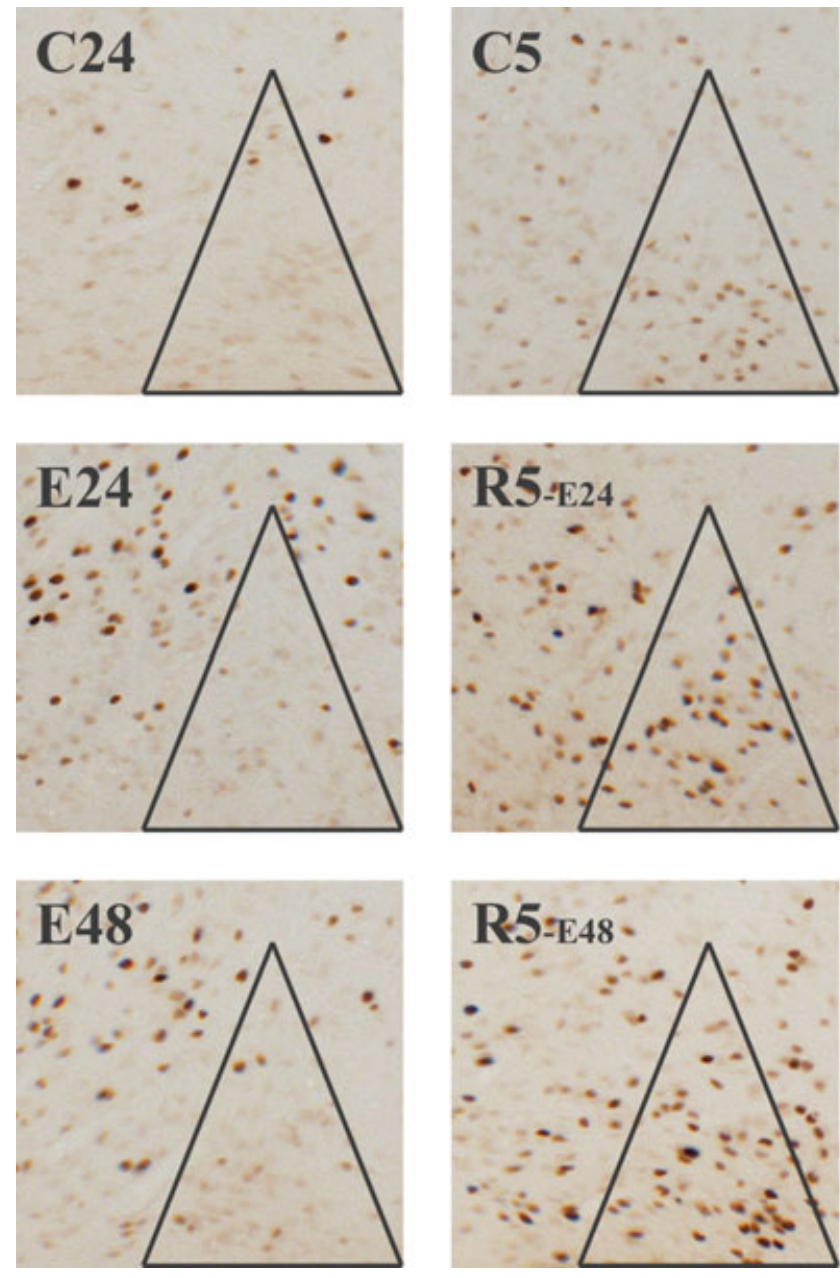

FIG. 6. Distribution of c-Fos-immunoreactive neurons (left) and phosphorylated cAMP/ $\mathrm{Ca}^{2+}$-responsive element-binding protein (P-CREB)-IRNs (right) for representative animals within the $300 \times 300 \mu \mathrm{m}$ square counting grid used for the ventrolateral preoptic nucleus (VLPO) cluster analysis. In both panels, the 5-h exposure condition (E5) is omitted. The triangular inset represents the $200 \times 250 \mu \mathrm{m}$ counting grid used by Lu et al. (2000) to better demarcate the VLPO GABAgalaninergic cell cluster for non-immunohistochemical quantifications. c-Fos-positive nuclei appear to have a characteristic pattern of distribution in relation to this triangular area within the square counting grid that we used for our immunohistochemical quantifications of the VLPO cluster: no stain was observed during the exposure, whereas a strong activation appeared during the following recovery. In contrast, P-CREB expression seems not to differentiate the VLPO cell cluster from the surrounding area, which would be better considered as belonging to the extended VLPO. C5, $5 \mathrm{~h}$ at an ambient temperature $\left(T_{\mathrm{a}}\right)$ of $23{ }^{\circ} \mathrm{C}$; C24, $24 \mathrm{~h}$ at a $T_{\mathrm{a}}$ of $23{ }^{\circ} \mathrm{C} ; \mathrm{E} 5,5 \mathrm{~h}$ at a $T_{2}$ of $-10{ }^{\circ} \mathrm{C}$; E24, $24 \mathrm{~h}$ at a $T_{2}$ of $-10{ }^{\circ} \mathrm{C} ; \mathrm{E} 48,48 \mathrm{~h}$ at a $T_{2}$ of $-10{ }^{\circ} \mathrm{C} ; \mathrm{R} 5$-E24, $5 \mathrm{~h}$ at a $T_{2}$ of $23{ }^{\circ} \mathrm{C}$ following $24 \mathrm{~h}$ at a $T_{2}$ of $-10{ }^{\circ} \mathrm{C} ; \mathrm{R} 5$-E $48,5 \mathrm{~h}$ at a $T_{\mathrm{a}}$ of $23^{\circ} \mathrm{C}$ following $48 \mathrm{~h}$ at a $T_{\mathrm{a}}$ of $-10{ }^{\circ} \mathrm{C}$.

As far as a discrimination between effects due to either REMS or NREMS deprivation/recovery is concerned, prolonged exposures to a $T_{\mathrm{a}}$ of $-10^{\circ} \mathrm{C}$ affect REMS occurrence to a larger extent than that of NREMS in rats. In particular, whereas REMS was practically suppressed up to $48 \mathrm{~h}$ of exposure (Amici et al., 1994, 1998; Cerri et al., 2005), NREMS was affected to a much lesser extent, even though a fragmentation of NREMS episodes and a decrease in delta activity were observed (Cerri et al., 2005) (present study, unpublished observations). Under these extreme conditions, the wake-sleep cycle is turned into a rapid sequence of unsuccessful transitions from NREMS to REMS, which are considered to be a sign of an increased pressure for REMS (Ocampo-Garcés et al., 2000; Franken, 2002). As shown in Fig. 3, during the recovery at normal laboratory $T_{\mathrm{a}}$ following either a $24-\mathrm{h}$ or 48 -h exposure, such a pressure led to a very intense REMS rebound, accompanied by a moderate increase in delta activity during NREMS, which is usually taken as an index of NREMS 'intensity' (Borbély \& Achermann, 2005), with no increase in time spent in NREMS. The size of the increase in delta power in relation to the baseline averaged around $55 \%$ and $25 \%$ from the third to the fifth hour of the recovery period in $R_{E 24}$ and $R_{E 48}$, respectively. This increase is far from the approximately $150 \%$ increase that was observed during the early recovery from $24 \mathrm{~h}$ of total sleep deprivation (Franken et al., 1991).

\section{c-Fos expression as a marker of sleep-related activity}

In the different nuclear divisions, no significant differences in c-Fos expression were found at lights-on (C24) as compared with $5 \mathrm{~h}$ after (C5). Thus, the daily oscillation in c-Fos levels, which have been shown to be higher in the VLPO and MnPO during the rest period (light) than during the activity period (dark) (Peterfi et al., 2004), did not become apparent within the 5-h time window of the present experiment. However, in the present study, this daily variation was close to significance $(P=0.055)$ in the VLPO cluster, and paralleled previous observations by Novak \& Nunez (1998), showing a higher c-Fos level in the VLPO cell cluster of animals killed $5 \mathrm{~h}$ after lights-on rather than $1 \mathrm{~h}$ after. Daily variations in cFos expression in the VLPO cluster have been convincingly shown 
TABLE 1. P-CREB expression in the VLPO and MnPO in the different experimental conditions

\begin{tabular}{lcc}
\hline & \multicolumn{2}{c}{ P-CREB expression (size of area in $\left.\mu \mathrm{m}^{2}\right)$} \\
\cline { 2 - 3 } Experimental condition & VLPO & MnPO \\
\hline C5 & $15979 \pm 4063^{\dagger}$ & $35386 \pm 6661^{\dagger}$ \\
C24 & $9522 \pm 2867$ & $16490 \pm 7486$ \\
E5 & $14147 \pm 3384$ & $41375 \pm 9925$ \\
E24 & $8603 \pm 2159$ & $29550 \pm 6728^{\mathrm{b}}$ \\
E48 & $9971 \pm 2846$ & $23916 \pm 1707^{\mathrm{b}}$ \\
R5-E24 & $10639 \pm 1439^{\mathrm{a}}$ & $31653 \pm 12359^{\mathrm{c}}$ \\
R5-E48 & $10001 \pm 1582^{\mathrm{a}}$ & $25578 \pm 11501^{\mathrm{c}}$ \\
\hline
\end{tabular}

Data are preseted as means \pm SEM. Experimental conditions: $\mathrm{C} 5,5 \mathrm{~h}$ at an ambient temperature $\left(T_{\mathrm{a}}\right)$ of $23^{\circ} \mathrm{C} ; \mathrm{C} 24,24 \mathrm{~h}$ at a $T_{\mathrm{a}}$ of $23^{\circ} \mathrm{C} ; \mathrm{E} 5,5 \mathrm{~h}$ at a $T_{\mathrm{a}}$ of $-10^{\circ} \mathrm{C}$; E24, $24 \mathrm{~h}$ at a $T_{\mathrm{a}}$ of $-10^{\circ} \mathrm{C} ; \mathrm{E} 48,48 \mathrm{~h}$ at a $T_{\mathrm{a}}$ of $-10^{\circ} \mathrm{C}$; R5-E24, $5 \mathrm{~h}$ at a $T_{\mathrm{a}}$ of $23^{\circ} \mathrm{C}$ following $24 \mathrm{~h}$ at a $T_{\mathrm{a}}$ of $-10^{\circ} \mathrm{C}$; R5-E $48,5 \mathrm{~h}$ at a $T_{\mathrm{a}}$ of $23^{\circ} \mathrm{C}$ following $48 \mathrm{~h}$ at a $T_{\mathrm{a}}$ of $-10^{\circ} \mathrm{C}$. Other abbreviations: P-CREB, phosphorylated cAMP $/ \mathrm{Ca}^{2+}$-responsive element-binding protein; MnPO, median preoptic nucleus; VLPO, ventrolateral preoptic nucleus. Statistically significant pre-planned contrasts and post hoc comparisons were as follows. ${ }^{\dagger} P<0.05$, for the comparison C5 vs. C24 (for VLPO, $t_{62}{ }^{*}=3.00, P=0.035$; and for MnPO, $\left.t_{62}{ }^{*}=2.94, P=0.041\right) .{ }^{\mathrm{a}, \mathrm{b}, \mathrm{c}} P<0.05$, comparing mean values of paired/ blocked data with the time-matched control. ${ }^{\mathrm{a}}$ For VLPO and (R5-E24/R5-E24) vs. $\mathrm{C} 5, F_{1,62}=5.41, P=0.023$. ${ }^{\mathrm{b}} \mathrm{For} \mathrm{MnPO}$ and (E24/E48) vs. C24 $F_{1,62}=4.21, P=0.044 .{ }^{\mathrm{c}}$ For MnPO and (R5-E24/R5-E24) vs. C5, $F_{1,62}=4.31$, $P=0.042$.

not to be circadian, but to be linked to sleep occurrence (Sherin et al., 1996).

Analysis of c-Fos expression across the experiment highlighted the presence of a sleep-related functional specificity for the VLPO cluster as compared with both the extended VLPO and the whole MnPO. In accordance with previous evidence (Cano et al., 2003), in both the $\mathrm{MnPO}$ and extended VLPO, c-Fos expression was increased as compared with the relative control levels after a 5-h exposure (E5). However, no changes were observed in the VLPO cluster. In addition, in the VLPO cluster only, the degree of activation during the recovery period was larger than that observed during the prolonged cold exposure. Interestingly, neurons active during either exposure or recovery showed a different pattern of distribution in relation to the triangular area (VLPO T-cluster) within the square counting grid, whose use has been proposed in order to give a better demarcation of the cluster itself (Lu et al., 2000). In particular, in our study, almost no stain was observed during the exposure within the VLPO T-cluster, whereas strong activation appeared during the recovery. Thus, during the prolonged exposure, the increase in c-Fos expression in the VLPO cluster counting grid as compared with control levels depended on the activation of neurons outside the sleep-active VLPO T-cluster.

This result not only confirms the strict relationship between the activation of this small group of neurons and sleep occurrence (Sherin et al., 1996; Szymusiak et al., 1998, 2007), but also points to the fact that VLPO T-cluster neurons are active during sleep and inactive during wakefulness, independently of the mechanism by which sleep deprivation and the subsequent recovery are induced. This is in agreement with the suggestion that the activation of VLPO T-cluster cells is related to sleep occurrence rather than to sleep pressure (Szymusiak et al., 1998, 2007; Saper et al., 2005). This lack of c-Fos expression during the exposure to a very low $T_{\mathrm{a}}$ may be explained by the fact that VLPO neurons are endowed with reciprocal inhibitory connections with the wakefulness-promoting areas (Fort et al., 2009) and/or by the lack of involvement of the VLPO T-cluster in thermoregulation-related processes ( $\mathrm{Lu}$ et al., 2000).
The functional complexity of both the VLPO and MnPO (Lu et al., 2000; Gvilia et al., 2005; Szymusiak et al., 2007) does not allow for the attribution of the strong activation of c-Fos expression during cold exposure in the whole $\mathrm{MnPO}$ and in the medial and dorsal extended VLPO to either thermoregulatory activation or increased sleep pressure, or to both, in particular in the absence of phenotyping of activated neurons. As it is known that neurons that are active during sleep in the MnPO are GABAergic, whereas those that, for example, are active during osmotic challenge are non-GABAergic (Gvilia et al., 2005), the possibility cannot be excluded that either thermoregulatory or sleep-related c-Fos expression may occur in different populations of cells in the same area.

The possibility that POA activation during cold exposure is, at least in part, due to an increase in sleep pressure is supported by a study in which the discharge rate of a relevant number of sleep-related $\mathrm{MnPO}$ neurons was shown to be related to the drive for sleep, as the rate progressively increased during wakefulness and declined during sleep (Suntsova et al., 2002). Furthermore, c-Fos expression in subsets of POA cells has shown to increase in proportion to the number of attempts to enter REMS under a selective REMS restriction protocol (Gvilia et al., 2006a). Finally, the connections and physiological activity of the extended VLPO suggest a specialized role in the regulation of REMS for this region (Koyama \& Hayaishi, 1994; Szymusiak et al., 1998; Lu et al., 2000, 2002). These data clearly indicate that previous interpretations of POA activation under a thermal challenge as simply thermoregulatory (Miyata et al., 1995; Bratincsak \& Palkovits, 2004) should be reconsidered. However, although our experimental conditions do not allow us to distinguish, during exposure, effects due to sleep pressure from those due to thermal load, the possible ambiguity in the interpretation of the results vanishes on consideration of the changes in antigen expression during the strong sleep rebound that occurs during the recovery period.

In this case, the intensification of sleep-related processes appears to be the main determinant of the increase in c-Fos expression that was observed in both the whole MnPO and the medial and dorsal extended VLPO. However, the difficulties in interpreting the c-Fos increase during the previous exposure prevent us from discriminating the contributions of sleep occurrence and/or increased sleep pressure in determining c-Fos increase during the recovery period. As previously discussed, under our experimental protocol, REMS is affected much more than NREMS. The possibility that the effects on c-Fos expression in both the VLPO and MnPO are linked to the REMS rebound is supported by experiments showing that c-Fos expression in subsets of POA cells increased in proportion to the intensity of the REMS rebound during the recovery that followed a selective REMS restriction protocol (Gvilia et al., 2006a).

The results of the present study show that changes in c-Fos expression and those in P-CREB levels are apparently dissociated. Up to now, P-CREB expression has never been investigated at the POA level. In the present experiment, P-CREB levels, but not c-Fos levels, were observed to vary significantly in control conditions in both nuclei, according to the time of day. Even though our experimental plan does not allow us to interpret this variation as being circadian, the presence of inputs from the suprachiasmatic nucleus, reaching the VLPO and MnPO through indirect projections via relays in the medial preoptic area, dorsomedial hypothalamic nucleus, and subparaventricular zone (Deurveilher et al., 2002; Deurveilher \& Semba, 2003), allows for the hypothesis that the suprachiasmatic nucleus has a direct influence on both nuclei.

Differently from what was observed for c-Fos expression, no changes in P-CREB expression as compared with the time-matched control levels were observed in the VLPO during the exposure, 
whereas an increase in P-CREB expression was observed in the MnPO only after prolonged exposure. Such a difference between the two nuclei may depend on different levels of involvement of the VLPO and $\mathrm{MnPO}$ in facing the ambient challenge on a long-term basis.

A clear dissociation between the changes in CREB phosphorylation and those in c-Fos expression was observed in both the VLPO and $\mathrm{MnPO}$ during the recovery period, as a decrease in P-CREB expression as compared with time-matched control levels was observed in both nuclei. Although P-CREB is a key activator of $c$-fos transcription, the induction of c-Fos expression can also be mediated by other pathways via different DNA-binding sites (Herdegen \& Leah, 1998). Thus, we can reasonably suppose that the sleep-related increase in c-Fos expression during the recovery period is not linked to a CREBmediated pathway. More interestingly, in contrast to what was observed for c-Fos expression, P-CREB expression did not appear to allow for the functional differentiation of the sleep-related activity of the VLPO T-cluster from that of the extended VLPO and the whole MnPO. Consequently, any sleep-related change in CREB phosphorylation in these nuclei does not seem to be related to sleep regulatory processes, but rather to a state-dependent modulation of P-CREB expression.

\section{Conclusions}

In conclusion, the pattern of changes in c-Fos expression that has been observed in the present study clearly indicates the involvement of both the VLPO and MnPO in the sleep regulatory processes that characterize the recovery period following a long-term physiological sleep deprivation protocol. In particular, the specificity of changes observed in the VLPO T-cluster support previous data indicating a role for this area in processes related to sleep occurrence. The dissociation between the changes in c-Fos expression and those in P-CREB levels, which are subject to state-related non-regulatory modulation, suggests that these changes in c-Fos expression do not depend on a P-CREBmediated pathway.

\section{Acknowledgements}

This article is dedicated to Christine Ann Jones, who made an important contribution to the experimental work but who sadly passed away before we submitted the manuscript. This work was supported by grants from both the Ministero dell'Università e della Ricerca Scientifica, Italy and the University of Bologna. The authors would like to thank R. Bartesaghi for permitting the use of image acquisition instrumentation and software for image analysis (IMAGE Pro Plus 4.5; Media Cybernetics). The authors would also like to thank G. Mancinelli and L. Sabattini for the electronic and mechanical work needed.

\section{Abbreviations}

$\mathrm{BL}$, baseline; $\mathrm{C} 24,24 \mathrm{~h}$ at an ambient temperature of $23^{\circ} \mathrm{C} ; \mathrm{C} 5,5 \mathrm{~h}$ at an ambient temperature of $23^{\circ} \mathrm{C}$; CREB, $\mathrm{Ca}^{2+} / \mathrm{cAMP}-$ responsive elementbinding protein; E24, $24 \mathrm{~h}$ at an ambient temperature of $-10^{\circ} \mathrm{C} ; \mathrm{E} 48,48 \mathrm{~h}$ at an ambient temperature of $-10^{\circ} \mathrm{C} ; \mathrm{E} 5,5 \mathrm{~h}$ at an ambient temperature of $-10^{\circ} \mathrm{C}$; EEG, electroencephalographic; IRN, immunoreactive neuron; MA, motor activity; MnPO, median preoptic nucleus; NREMS, non-rapid eye movement sleep; P-CREB, phosphorylated form of the cAMP/ $\mathrm{Ca}^{2+}$ responsive element-binding protein; POA, preoptic area; R5-E24, $5 \mathrm{~h}$ at an ambient temperature of $23{ }^{\circ} \mathrm{C}$ following $24 \mathrm{~h}$ at an ambient temperature of $-10^{\circ} \mathrm{C}$; R5-E48, $5 \mathrm{~h}$ at an ambient temperature of $23^{\circ} \mathrm{C}$ following $48 \mathrm{~h}$ at an ambient temperature of $-10^{\circ} \mathrm{C} ; \mathrm{R}_{\mathrm{E} 24}, 5$-h period at an ambient temperature of $25^{\circ} \mathrm{C}$ following $24 \mathrm{~h}$ at an ambient temperature of $-10^{\circ} \mathrm{C}$; $\mathrm{R}_{\mathrm{E} 48}$, 5-h period at an ambient temperature of $25^{\circ} \mathrm{C}$ following $48 \mathrm{~h}$ at an ambient temperature of $-10^{\circ} \mathrm{C}$; REMS, rapid eye movement sleep; $t^{*}$, modified $t$-statistic; $T_{\mathrm{a}}$, ambient temperature; $T_{\text {hy }}$, hypothalamic temperature; VLPO, ventrolateral preoptic nucleus.

\section{References}

Alam, M.N., McGinty, D. \& Szymusiak, R. (1995a) Neuronal discharge of preoptic/anterior hypothalamic thermosensitive neurons: relation to NREM sleep. Am. J. Physiol., 269, R1240-R1249.

Alam, M.N., McGinty, D. \& Szymusiak, R. (1995b) Preoptic/anterior hypothalamic neurons: thermosensitivity in rapid eye movement sleep. Am. J. Physiol., 269, R1250-R1257.

Alam, M.N., McGinty, D. \& Szymusiak, R. (1996) Preoptic/anterior hypothalamic neurons: thermosensitivity in wakefulness and non rapid eye movement sleep. Brain Res., 718, 76-82.

Amici, R., Zamboni, G., Perez, E., Jones, C.A., Toni, I.I., Culin, F. \& Parmeggiani, P.L. (1994) Pattern of desynchronized sleep during deprivation and recovery induced in the rat by changes in ambient temperature. J. Sleep Res., 3, 250-256.

Amici, R., Zamboni, G., Perez, E., Jones, C.A. \& Parmeggiani, P.L. (1998) The influence of a heavy thermal load on REM sleep in the rat. Brain Res., 781, $252-258$.

Amici, R., Cerri, M., Ocampo-Garcés, A., Baracchi, F., Dentico, D., Jones, C.A., Luppi, M., Perez, E., Parmeggiani, P.L. \& Zamboni, G. (2008) Cold exposure and sleep in the rat: REM sleep homeostasis and body size. Sleep, 31, 708-715.

Borbély, A. \& Achermann, P. (2005) Sleep homeostasis and models of sleep regulation. In Kryger, M., Roth, T. \& Dement, W.C. (ed.), Principles and Practice of Sleep Medicine. Elsevier Saunders, Philadelphia, pp. 405-417.

Bratincsak, A. \& Palkovits, M. (2004) Activation of brain areas in rat following warm and cold ambient exposure. Neuroscience, 127, 385-397.

Brown, E.R. \& Sawchenko, P.E. (1997) Hypophysiotropic CRF neurons display a sustained immediate-early gene response to chronic stress but not to adrenalectomy. J. Neuroendocrinol., 9, 307-316.

Cano, G., Passerin, A.M., Schiltz, J.C., Card, J.P., Morrison, S.F. \& Sved, A.F. (2003) Anatomical substrates for the central control of sympathetic outflow to interscapular adipose tissue during cold exposure. J. Comp. Neurol., 460, 303-326.

Cerri, M., Ocampo-Garcés, A., Amici, R., Baracchi, F., Capitani, P., Jones, C.A., Luppi, M., Perez, E., Parmeggiani, P.L. \& Zamboni, G. (2005) Cold exposure and sleep in the rat: effects on sleep architecture and the electroencephalogram. Sleep, 28, 694-705.

Del Sindaco, E., Baracchi, F., Cerri, M., Dentico, D., Luppi, M., Martelli, D., Perez, E. \& Amici, R. (2006) Long-term aspects of REM sleep regulation in the rat. J. Sleep Res., 15, 99-100.

Dentico, D., Jones, C.A., Del Sindaco, E., Laudadio, S., Luppi, M., Martelli, D., Perez, E. \& Zamboni, G. (2008a) An integrative role of the median preoptic nucleus in sleep deprivation and recovery induced by low ambient temperature. J. Sleep Res., 17, P401.

Dentico, D., Jones, C.A., Amici, R., Baracchi, F., Cerri, M., Perez, E., Tupone, D. \& Zamboni, G. (2008b) Sleep related activation of the ventrolateral preoptic nucleus following the exposure to low ambient temperature. J. Sleep Res., 17, P467.

Deurveilher, S. \& Semba, K. (2003) Indirect projections from the suprachiasmatic nucleus to the median preoptic nucleus in rat. Brain Res., 987, 100106.

Deurveilher, S., Burns, J. \& Semba, K. (2002) Indirect projections from the suprachiasmatic nucleus to the ventrolateral preoptic nucleus: a dual tracttracing study in rat. Eur. J. Neurosci., 16, 1195-1213.

Fort, P., Bassetti, C.L. \& Luppi, P.H. (2009) Alternating vigilance states: new insights regarding neuronal networks and mechanisms. Eur. J. Neurosci., 29, $1741-1753$.

Franken, P. (2002) Long-term vs. short-term processes regulating REM sleep. J. Sleep Res., 11, 17-28.

Franken, P., Dijk, D.J., Tobler, I. \& Borbély, A.A. (1991) Sleep deprivation in rats: effects on EEG power spectra, vigilance states, and cortical temperature. Am. J. Physiol., 261, R198-R208.

Geisler, S., Heilmann, H. \& Veh, R.W. (2002) An optimized method for simultaneous demonstration of neurons and myelinated fiber tracts for delineation of individual trunco- and palliothalamic nuclei in the mammalian brain. Histochem. Cell Biol., 117, 69-79.

Gong, H., Szymusiak, R., King, J., Steininger, T. \& McGinty, D. (2000) Sleeprelated c-Fos protein expression in the preoptic hypothalamus: effects of ambient warming. Am. J. Physiol. Regul. Integr. Comp. Physiol., 279, R2079-R2088.

Gong, H., McGinty, D., Guzman-Marin, R., Chew, K.T., Stewart, D. \& Szymusiak, R. (2004) Activation of c-fos in GABAergic neurones in the preoptic area during sleep and in response to sleep deprivation. J. Physiol., 556, 935-946. 
Guillery, R.W. \& Herrup, K. (1997) Quantification without pontification: choosing a method for counting objects in sectioned tissues. J. Comp. Neurol., 386, 2-7.

Gvilia, I., Angara, C., McGinty, D. \& Szymusiak, R. (2005) Different neuronal populations of the rat median preoptic nucleus express c-fos during sleep and in response to hypertonic saline or angiotensin-II. J. Physiol., 569, 587-599.

Gvilia, I., Turner, A., McGinty, D. \& Szymusiak, R. (2006a) Preoptic area neurons and the homeostatic regulation of rapid eye movement sleep. J. Neurosci., 26, 3037-3044.

Gvilia, I., Xu, F., McGinty, D. \& Szymusiak, R. (2006b) Homeostatic regulation of sleep: a role for preoptic area neurons. J. Neurosci., 26, 94269433.

Heller, H. (2005) Temperature, thermoregulation, and sleep. In Kryger, M., Roth, T. \& Dement, W.C. (ed.), Principles and Practice of Sleep Medicine. Elsevier Saunders, Philadelphia, pp. 292-304.

Herdegen, T. \& Leah, J.D. (1998) Inducible and constitutive transcription factors in the mammalian nervous system: control of gene expression by Jun, Fos and Krox, and CREB/ATF proteins. Brain Res. Brain Res. Rev., 28, $370-490$.

Hoffman, G.E. \& Lyo, D. (2002) Anatomical markers of activity in neuroendocrine systems: are we all 'fos-ed out'? J. Neuroendocrinol., 14, 259-268.

Holm, S. (1979) A simple sequentially rejective multiple test procedure. Scand. J. Stat., 6, 65-70.

Kovács, K.J. \& Sawchenko, P.E. (1996) Sequence of stress-induced alterations in indices of synaptic and transcriptional activation in parvocellular neurosecretory neurons. J. Neurosci., 16, 262-273.

Koyama, Y. \& Hayaishi, O. (1994) Firing of neurons in the preoptic/anterior hypothalamic areas in rat: its possible involvement in slow wave sleep and paradoxical sleep. Neurosci. Res., 19, 31-38.

Lu, J., Greco, M.A., Shiromani, P. \& Saper, C.B. (2000) Effect of lesions of the ventrolateral preoptic nucleus on NREM and REM sleep. J. Neurosci., 20, 3830-3842.

Lu, J., Bjorkum, A.A., Xu, M., Gaus, S.E., Shiromani, P.J. \& Saper, C.B. (2002) Selective activation of the extended ventrolateral preoptic nucleus during rapid eye movement sleep. J. Neurosci., 22, 4568-4576.

McKinley, M.J., Hards, D.K. \& Oldfield, B.J. (1994) Identification of neural pathways activated in dehydrated rats by means of Fos-immunohistochemistry and neural tracing. Brain Res., 653, 305-314.

Miyata, S., Nakashima, T. \& Kiyohara, T. (1994) Expression of c-fos immunoreactivity in the hypothalamic magnocellular neurons during chronic osmotic stimulations. Neurosci. Lett., 175, 63-66.

Miyata, S., Ishiyama, M., Shido, O., Nakashima, T., Shibata, M. \& Kiyohara, T. (1995) Central mechanism of neural activation with cold acclimation of rats using Fos immunohistochemistry. Neurosci. Res., 22, 209-218.

Morgan, J.I. \& Curran, T. (1991) Stimulus-transcription coupling in the nervous system: involvement of the inducible proto-oncogenes fos and jun. Annu. Rev. Neurosci., 14, 421-451.

Nakamura, K. \& Morrison, S.F. (2008) Preoptic mechanism for cold-defensive responses to skin cooling. J. Physiol., 586, 2611-2620.

Novak, C.M. \& Nunez, A.A. (1998) Daily rhythms in Fos activity in the rat ventrolateral preoptic area and midline thalamic nuclei. Am. J. Physiol., 275, R1620-R1626.

Ocampo-Garcés, A., Molina, E., Rodriguez, A. \& Vivaldi, E.A. (2000) Homeostasis of REM sleep after total and selective sleep deprivation in the rat. J. Neurophysiol., 84, 2699-2702.

Parmeggiani, P.L. (1987) Interaction between sleep and thermoregulation: an aspect of the control of behavioral states. Sleep, 10, 426-435.

Parmeggiani, P.L. (2003) Thermoregulation and sleep. Front. Biosci., 8, s557s567.

Parmeggiani, P.L., Cevolani, D., Azzaroni, A. \& Ferrari, G. (1987) Thermosensitivity of anterior hypothalamic-preoptic neurons during the wakingsleeping cycle: a study in brain functional states. Brain Res., 415, 79-89.
Patronas, P., Horowitz, M., Simon, E. \& Gerstberger, R. (1998) Differential stimulation of c-fos expression in hypothalamic nuclei of the rat brain during short-term heat acclimation and mild dehydration. Brain Res., 798, $127-139$.

Paxinos, G. \& Watson, C. (1998) The Rat Brain in Stereotaxic Coordinates. Academic Press, Sydney.

Paxinos, G. \& Watson, C. (2005) The Rat Brain in Stereotaxic Coordinates. Academic Press, Sydney.

Peterfi, Z., Churchill, L., Hajdu, I., Obal, F. Jr, Krueger, J.M. \& Parducz, A. (2004) Fos-immunoreactivity in the hypothalamus: dependency on the diurnal rhythm, sleep, gender, and estrogen. Neuroscience, 124, 695-707.

Romanovsky, A.A. (2007) Thermoregulation: some concepts have changed. Functional architecture of the thermoregulatory system. Am. J. Physiol. Regul. Integr. Comp. Physiol., 292, R37-R46.

Saper, C.B., Scammell, T.E. \& Lu, J. (2005) Hypothalamic regulation of sleep and circadian rhythms. Nature, 437, 1257-1263.

Sharp, F.R., Sagar, S.M., Hicks, K., Lowenstein, D. \& Hisanaga, K. (1991) c-fos mRNA, Fos, and Fos-related antigen induction by hypertonic saline and stress. J. Neurosci., 11, 2321-2331.

Sherin, J.E., Shiromani, P.J., McCarley, R.W. \& Saper, C.B. (1996) Activation of ventrolateral preoptic neurons during sleep. Science, 271, 216-219.

Sherin, J.E., Elmquist, J.K., Torrealba, F. \& Saper, C.B. (1998) Innervation of histaminergic tuberomammillary neurons by GABAergic and galaninergic neurons in the ventrolateral preoptic nucleus of the rat. J. Neurosci., 18, 4705-4721.

Snedecor, G. \& Cochran, W.G. (1991) Statistical Methods. Iowa State University Press, Ames.

Steininger, T.L., Gong, H., McGinty, D. \& Szymusiak, R. (2001) Subregional organization of preoptic area/anterior hypothalamic projections to arousalrelated monoaminergic cell groups. J. Comp. Neurol., 429, 638-653.

Suntsova, N., Szymusiak, R., Alam, M.N., Guzman-Marin, R. \& McGinty, D. (2002) Sleep-waking discharge patterns of median preoptic nucleus neurons in rats. J. Physiol., 543, 665-677.

Suntsova, N., Guzman-Marin, R., Kumar, S., Alam, M.N., Szymusiak, R. \& McGinty, D. (2007) The median preoptic nucleus reciprocally modulates activity of arousal-related and sleep-related neurons in the perifornical lateral hypothalamus. J. Neurosci., 27, 1616-1630.

Szymusiak, R., Alam, N., Steininger, T.L. \& McGinty, D. (1998) Sleep-waking discharge patterns of ventrolateral preoptic/anterior hypothalamic neurons in rats. Brain Res., 803, 178-188.

Szymusiak, R., Gvilia, I. \& McGinty, D. (2007) Hypothalamic control of sleep. Sleep Med., 8, 291-301.

Uschakov, A., Gong, H., McGinty, D. \& Szymusiak, R. (2007) Efferent projections from the median preoptic nucleus to sleep- and arousalregulatory nuclei in the rat brain. Neuroscience, 150, 104-120.

Wallenstein, S., Zucker, C.L. \& Fleiss, J.L. (1980) Some statistical method useful in circulation research. Circ. Res., 47, 1-9.

Wu, G.Y., Deisseroth, K. \& Tsien, R.W. (2001) Activity-dependent CREB phosphorylation: convergence of a fast, sensitive calmodulin kinase pathway and a slow, less sensitive mitogen-activated protein kinase pathway. Proc. Natl Acad. Sci. USA, 98, 2808-2813.

Zamboni, G., Jones, C.A., Amici, R., Perez, E. \& Parmeggiani, P.L. (1996) The capacity to accumulate cyclic AMP in the preoptic-anterior hypothalamic area of the rat is affected by the exposition to low ambient temperature and the subsequent recovery. Exp. Brain Res., 109, 164-168.

Zamboni, G., Perez, E., Amici, R., Jones, C.A. \& Parmeggiani, P.L. (1999) Control of REM sleep: an aspect of the regulation of physiological homeostasis. Arch. Ital. Biol., 137, 249-262.

Zamboni, G., Jones, C.A., Domeniconi, R., Amici, R., Perez, E., Luppi, M., Cerri, M. \& Parmeggiani, P.L. (2004) Specific changes in cerebral second messenger accumulation underline REM sleep inhibition induced by the exposure to low ambient temperature. Brain Res., 1022, 62-70. 